ISSN: $2146-3042$

DOI: $10.25095 /$ mufad.607173

\title{
Türkiye’de Büyük ve Orta Ölçekli İşletmeler İçin Finansal Raporlama Standartlarına Göre İhtiyatlılık İlkesinin Uygulanması*
}

\author{
Ümit GÜCENME GENÇOĞLU** \\ Yusuf KURT ${ }^{* * *}$
}

ÖZET

Türkiye'de Kamu Gözetimi, Muhasebe Ve Denetim Standartları Kurumu ( KGK) düzenlemelerine göre, kamu yararını ilgilendiren kuruluşların finansal tabloları Uluslararası Finansal Raporlama Standartlartyla (International Financial Reporting Standarts- IFRS) tam uyumlu Türkiye Finansal Raporlama Standartlarına (TFRS) göre düzenlenir. Bağımsız denetime tabi olup TFRS uygulamayan işletmelerin ise finansal tablolarını Büyük ve Orta Ölçekli Iş̧letmeler için Finansal Raporlama Standartlarına (BOBI FRS) göre hazırlamalar gerekmektedir. TFRS ve BOBI FRS'de ihtiyaca uygun finansal raporlama için güncel ve karşılaştırılabilir bilgi sunmak temel amaç olmakla birlikte işletmelerin risklere karşı korunabilmesi için ihtiyatlllık ilkesine uygun davranması istenmektedir. Bu çalışmanın amacı, Türkiye'de 2018 yll başından itibaren uygulanan BOBI FRS'de ihtiyatlllık ilkesinin uygulanmasina ilişkin düzenlemelerin ortaya konmasıdır.

Anahtar kelimeler: Finansal raporlama standartları, ihtiyatlllık ilkesi, işletmenin sürekliliği

JEL Sinıflandirması: M40, M41, M42

Implementatıon of Conservatism Principle According to Financial Reporting Standards for Large and Medium-Sized Enterpries in Turkey

ABSTRACT

According to the regulations of Public Oversight Accounting and Auditing Standards Authority, financial statements of public interestentity are prepared according toTurkish Financial Reporting Standards that is compatible with International Financial Reporting Standards- IFRS. Companiesin dependently audited and do not apply Turkish Financial Reporting Standards should prepare their financial statements according to Financial Reporting Standards for Large and Medium-sized Entities(BOBI FRS). The main aim forfinancialreporting in TFRS and Financial Reporting Standard for Large and Medium-sized Entities is to present current and comparable in formation that is appropriate for users the financial statement and demand that these businesses should be have according to the conservatism principle for protection again strisks. The aim of thisstudy is topresenttheregulations on the implementation of the conservatism principle in the Financial Reporting Standards for Large and MediumSized Entities.

Keywords: Financial reporting standards, conservatism principle, continuity of businesses

JEL Classification: M40, M41, M42

Makale Gönderim Tarihi: 01.06.2019

Makale Kabul Tarihi: 01.08.2019

Makale Türü: Kuramsal (Teorik) Makale

\footnotetext{
* Bu çalışma V. Uluslararası Muhasebe ve Finans Sempozyumunda sunulmuştur. (ISAF 2019, 1-4 May, Bursa, Türkiye).

Prof.Dr. Ümit GÜCENME GENÇOĞLU, Bursa Uludağ Üniversitesi, umitgucenme@uludag.edu.tr, ORCID ID: 0000-0002-8034-9063

**** Bursa Uludağ Üniversitesi Sosyal Bilimler Enstitüsü, krtysf61@gmail.com
} 


\section{GIRIŞ}

İhtiyatlılık kavramı, muhasebe olaylarında temkinli davranılması ve işletmenin karşılaşabileceği risklerin göz önüne alınması gereğini ifade eder. İşletme sürekliliğinin sağlanabilmesi için uyulması gereken temel ilke olan ihtiyatlılık kavramı ile varlık ve yükümlülüklerin cari değerleri ile raporlanması esasına dayanan gerçeğe uygun sunum ilkesinin birbirine karşıt etki yaratacağı tartışmaları bulunsa da, muhasebe standartlarında ihtiyatlılık ilkesi korunmuştur. İhtiyatlılık ilkesine göre, varlıkların olduğundan yüksek, borçların da olduğundan düşük raporlanmaması yoluyla karın olduğundan yüksek hesaplanmaması tavsiye edilmektedir. Bunun için varlıklardaki değer azalışları bilançoda raporlanmalı ve bu değer azalışları için karşılık ayrılarak gider kaydedilmesi suretiyle olası gider ve zararların kayıtlanıp raporlanması sağlanmalıdır. Ayrıca kesinleşen borçlar ile birlikte işletmenin olası borçları da raporlanmalı, olası borçlar için de karşılık ayrılarak gider kaydedilmelidir. Böylece giderler ve borçlar kesinleşen ve olası tutarları ile kayıtlanıp raporlanır. İhtiyatlılık ilkesine göre, gelirler ve alacaklar ise sadece kesinleşen tutarları ile kayıtlanmalı ve raporlanmalıdır. Buna göre işletmelerin ana hedefi gelirleri maksimize etmek ve bu gelirlerin bir kısmını işletme bünyesinde tutmak olmalıdır. Bu şekilde gerçekleştirilen gizli otofinansman, işletme için maliyeti olmayan en değerli fon kaynağını oluşturmaktadır. Gizli otofinansman olanaklarının Türkiye'de 2018 yılı başından itibaren uygulanan BOBİ FRS'de ne şekilde yer aldığının tespiti bu çalışmanın ana amacını oluşturmaktadır.

\section{TÜRKIYYE'DE TFRS VE BOBİ FRS}

Dünyada finansal raporlamaya yön veren ve Uluslararası Muhasebe Standartları Kurulu (IASB) tarafindan oluşturulan Uluslararası Finansal Raporlama Standartları(UFRS) tek otorite olma yolunda emin adımlarla ilerlemektedir. IASB'nin 2017 Şubat ayında yayınladığı analize göre; dünya genelindeki belli başlı 88 menkul kıymet borsasında işlem gören 49.000 adet işletmeden 27.000'i UFRS'leri kullanmaktadır. UFRS'leri kullanmayan işletmelerin yaklaşık \% 90'ının ise Çin, Hindistan, Japonya ve ABD'den olduğu aynı analizde belirtilmektedir(Ataman,2017:12)

Ortak bir muhasebe dili oluşturmak amacına yönelik oluşturulan UFRS'ler, zamanla "ortak bir finansal raporlama sistemi oluşturmak" amacına hizmet etmeye başlamıştır. UFRS'lerin ilk uygulaması yalnızca borsada işlem gören işletmeler ile sınırlıken, zaman içerisinde kamuya hesap verme zorunluluğu bulunmayan işletmeler için de finansal raporlama seti oluşturulması yönünde bir beklenti oluşmuştur(Gökçen vd.,2018:437).Uluslararası Finansal Raporlama Standartları, ilk kez Sermaye Piyasası Kurulu Tebliği ile Türkiye mevzuatına girmiştir. Sermaye Piyasası Kanunu'na tabi kurumlar UFRS ile uyumlu olan Sermaye Piyasası Kurulu Seri:XI, No: 25 Tebliğini 1.1.200509.04.2008 tarihleri arasında uygulamışlar ve bağımsız denetime tabi olmuşlardır. Daha sonra bu işletmelerin finansal raporlarını, Türkiye Muhasebe Standartları Kurulu (TMSK) tarafindan UFRS'lerin tercümesi olarak hazırlanan ve Resmi Gazete'de yayımlanan Tam Set Muhasebe Standartlarına göre hazırlamaları zorunluluğu getirilmiştir(Gücenme Gençoğlu,2017:2) 2002 yılında faaliyete geçen TMSK, 2011 yılında lağvedilmiş ve faaliyetleri durdurularak tüm yetkileri 2 Kasım 2011 tarihli Kanun Hükmünde Kararname ile kurulan Kamu Gözetimi, Muhasebe Ve Denetim Standartları Kurumu (KGK)'na devredilmiştir.14 Şubat 2011'de Resmi Gazete'de yayımlanan ve 1 Temmuz 2012 tarihinde yürürlüğe giren 6102 sayılı Türk Ticaret Kanunu'na göre kamu yararını ilgilendiren, sermaye 
piyasasında faaliyette bulunan ve 2005 yılından itibaren bağımsız muhasebe denetimine tabi olan işletmelerin finansal tabloları, Türkiye Finansal Raporlama Standartlarına (TFRS) göre düzenlenmektedir. Bağımsız denetime tabi olup, sermaye piyasasında faaliyette bulunmayan ve bu nedenle TFRS'leri uygulamayan işletmeler, 1 Ocak 2018 tarihi ve sonrasında başlayan yıllık hesap dönemlerinde KGK tarafından yayımlanan "Büyük ve Orta Boy Isşletmeler için Finansal Raporlama Standardı"nı uygulamak zorundadır(KGK, http://www.kgk.gov.tr).29 Temmuz 2017 tarihli BOBİ FRS Hakkında Tebliğ'e göre, aktif toplamı 75 milyon ve üstü, yıllık net satış hasılatı 150 milyon ve üstü Türk Lirası ve ortalama çalışan sayısı 250 ve üstü olan ve bu üç ölçütten en az ikisini, varsa bağlı ortaklıklarıyla birlikte, art arda iki raporlama döneminde aşan işletmeler ertesi raporlama döneminde büyük işletme olarak değerlendirilir. $\mathrm{Bu}$ ölçütlerin altında kalan, ancak denetime tabi olma koşullarını karşılayan işletmeler ise standartta orta boy işletmelerin uyması gereken kurallara göre finansal raporlama yapmaktadir.

Uluslararası muhasebe ve finansal raporlama uygulamalarıyla ve AB düzenlemeleriyle uyumlu olan ve 27 bölümden oluşan BOBİ FRS'de, orta büyüklükteki işletmeler için genel olarak maliyet esaslı bir finansal raporlama öngörülmüş; büyük işletmelere yönelik ise ilâve yükümlülükler getirilmiştir. BOBİ FRS'de yer alan kavramsal çerçeve ve finansal tablolar ile ilgili düzenlemeler genel olarak Türkiye Finansal Raporlama Standartları ile uyumludur. Buna göre, bir finansal bilginin faydalı olması için temel olarak, bilgiyi kullanacakların ihtiyacına ve işletme gerçeklerine uygun olmalı ve ayrıca bu bilgiler zamanında sunulmalı, anlaşılabilir ve karşılaştırılabilir olmalıdır. İhtiyatlılık ilkesine uyularak, belirsizlikler nedeniyle tahmin yapılması gereken hallerde varlık ve gelirlerin olduğundan daha fazla, yükümlülük ve giderlerin ise olduğundan daha düşük belirlenmemesi için gerekli dikkatin gösterilmesi gerekir. Genel finansal raporlama ilkeleri, tam set ile uyumlu tanımlar içinde işletmenin sürekliliği, tahakkuk esası ve ihtiyatlılık olarak sıralanmış ve finansal tabloların sunumunda önemlilik ve mahsup yasağı tanımları verilmiştir.

\section{BOBİ FRS'DE GERÇEĞE UYGUN DEĞER VE İHTIYATLILIK İLKESİ İLE İLGILII DÜZENLEMELER}

BOBİ FRS'ye göre, gerçeğe uygun değer gibi başka bir ölçüm esası belirlenmediği sürece, varlık ve yükümlülükler ilk kayda almada maliyet bedeli (tarihi maliyet) ile ölçülür. BOBİ FRS'de gerçeğe uygun değer, karşılıklı pazarlık ortamında, bilgili ve istekli taraflar arasında bir varlığın el değiştirmesi ya da bir yükümlülüğün yerine getirilmesi durumunda ortaya çıkabilecek tutarı ifade eder. Farklı varlık ve yükümlülükler için gerçeğe uygun değerin belirlenmesi için farklı bölümler içinde ayrıntılı açıklamalar yapılmıştır.

TFRS ile uyumlu olarak BOBİ FRS'de bir yandan ihtiyatlllık ilkesi korunurken, bir yandan da varlıkların ve borçların raporlama tarihindeki gerçeğe uygun değerinin ölçülmesi, böylece ihtiyaca uygun bilgi sunulması amaçlanmaktadır. Varlıkların yükselen cari değeriyle ölçülmesi ihtiyatlılık ilkesine ters görünse de, bununla ilgili düzenlemelerin ayrıntısına bakıldığında hem gerçeğe uygun sunumun hem de ihtiyatlılık ilkesinin birlikte uygulandığı görülmektedir. İhtiyatlılık ilkesinin gereği olan varlıkların ve gelirlerin olduğundan yüksek, borçların ve giderlerin olduğundan düşük raporlanmamasına ilişkin BOBİ FRS'de yer alan düzenlemeler aşağıdaki gibi özetlenebilir. 


\subsection{Varlıkların ve Gelirlerin Olduğundan Yüksek Raporlanmaması}

BOBİ FRS 6. Bölümde ele alınan stokların maliyeti, tüm satın alma maliyetlerini, dönüştürme maliyetlerini ve stokların bulunduğu yere ve mevcut durumuna getirilmesi için katlanılan diğer maliyetleri içerir. Bir yıl veya daha kısa vadeli bir ödeme karşılığında satın alınan stoklar için vade farkı ayrıştırılmaz, ancak bir yıldan uzun vadeli bir ödeme karşılığında satın alınan stoklarda vade farkı ayrıştırılır ve bu stoklar peşin fiyat üzerinden (diğer bir ifadeyle işletme peşin ödeme yapmış olsaydı ödeyeceği fiyat üzerinden) ölçülür. Bu durumda vade farkı tutarı, etkin faiz yöntemine göre hesaplanarak, faiz gideri olarak muhasebeleştirilir. Her raporlama dönemi sonunda, stokların değer düşüklüğüne uğrayıp uğramadığı değerlendirilir. Stokların değer düşüklügüne uğraması durumunda, stokların defter değeri net gerçekleşebilir değerine indirilir. Bu indirim tutarı, değer düşüklüğü zararını oluşturur ve Kâr veya Zarar Tablosunda "Satışların Maliyeti" kalemine yansıtılır. Bu düzenlemeler gereği stoklar aktifte düşük değer ile raporlanmakta, stokların maliyeti içinde yer almayan vade farkı ve değer düşüklüğü zararı, gider olarak kar zarar tablosunda raporlanmaktadır.

BOBİ FRS 7. Bölümde canlı varlıkların bir muhasebe politikası tercihi olarak gerçeğe uygun değer yöntemi(satış maliyetleri düşülmüş gerçeğe uygun değer ) ya da maliyet yöntemi kullanılarak ölçüleceği belirtilmektedir. Gerçeğe uygun değer yönteminin tercih edilmesi durumunda bir canlı varlık ilk kayda almada ve her bir raporlama dönemi sonunda satış maliyetleri düşülmüş gerçeğe uygun değeri üzerinden ölçülür. Gerçeğe uygun değerinde meydana gelen değişikliklerden kaynaklanan kazanç veya kayıplar kâr veya zarara yansıtılır. Maliyet yönteminin tercih edilmesi durumunda canlı varlıklar "Maddi Duran Varlıklar" bölümündeki gibi amortismana tabi tutulur ve maliyet bedelinden amortisman ve birikmiş değer düşüklüğü zararları düşülerek hesaplanan tutarları üzerinden ölçülür.

BOBİ FRS 9. Bölümde finansal varlık ve yükümlülükler ele alınmakta, bir yıldan uzun vadeli olan alacak ve borçların itfa edilmiş değeri üzerinden ölçüleceği ve etkin faiz yöntemine göre hesaplanan faiz tutarının kâr veya zarar tablosunda raporlanacağı belirtilmektedir. Ayrıca bunlar dışında kalan, bankalardaki vadeli mevduatlar, devlet tahvili, hazine bonosu veya özel sektör tahvil ve bonoları gibi borçlanma aracı niteliğindeki finansal varlıklar ile alınan krediler, ihraç edilen tahvil ve bonolar gibi finansal yükümlülükler de itfa edilmiş değeri üzerinden ölçülür ve raporlanır.

İşletmenin aldığı hisse senetleri, eğer borsada ve/veya teşkilatlanmış diğer piyasalarda işlem görüyorsa, raporlama tarihinde gerçeğe uygun değerleri (piyasa değeri) üzerinden ölçülür ve ortaya çıkan değer farkları kâr veya zarara yansıtılır. Borsada ve/veya teşkilatlanmış diğer piyasalarda işlem görmeyen hisse senedi yatırımları ise, gerçeğe uygun değeri ile değil, maliyet bedeli ile ve varsa değer düşüklüğü zararları düşülerek ölçülür.

Gerçeğe uygun değeri üzerinden ölçülen finansal varlıklar dışında kalan dolayısıyla itfa edilmiş değeri, maliyet bedeli veya itibari değeri üzerinden ölçülen tüm finansal varlıklara ilişkin değer düşüklüğü hükümleri de bu bölümde düzenlenmektedir. Raporlama dönemi sonlarında söz konusu finansal varlıkların değer düşüklüğüne uğradığına dair gözlemlenebilir bir kanıtın bulunup bulunmadığı değerlendirilir. Değer düşüklüğüne dair gözlemlenebilir bir kanıt bulunduğunda, değer düşüklüğü zararı kar zarar tablosuna yansitılır. 
Türev finansal araçlar ile ilgili, BOBİ FRS Bölüm 9 madde 46 ve 53'de belirtilen şartların sağlanması durumunda işletme, isteğe bağlı olarak korunma muhasebesi uygulayabilir. Bu durumda korunma aracının gerçeğe uygun değerindeki değişimin, korunan kalemin gerçeğe uygun değerindeki veya beklenen nakit akışlarındaki değişimleri etkin olarak karşılayan kısmı, özkaynaklarda "Korunma Yedeği" kaleminde muhasebeleştirilir. Özkaynaklarda kayda alınan korunma kazanç veya kaybı,

- $\quad$ Korunma aracının süresinin dolması, satılması veya feshedilmesi,

- $\quad$ Korunma işleminin korunma muhasebesi şartlarını artık karşılamaması,

- $\quad$ Tahmini bir işleme ilişkin korunma işleminde, bu tahmini işlemin gerçekleşme ihtimalinin artık yüksek olmaması veya

- $\quad$ Isşletmenin korunma muhasebesinden vazgeçmesi durumunda, ya da;korunan kalem kâr veya zararı etkilediğinde veya korunma ilişkisi sona erdiğinde, kâr veya zarara aktarılır. Buna karşılık özkaynaklarda kayda alınan yurtdışındaki net yatırımdan korunma işlemine ilişkin toplam kur farkı tutarı, bu yatırım elden çıkarıldığında ihtiyatlılık ilkesine uygun olarak "Geçmiş Yıllar Kârları/Zararları” kalemine aktarılır

BOBİ FRS 12. ve 14 bölümlere göre, maddi ve maddi olmayan duran varlıklar, bir y1l veya daha kısa vadeli bir ödeme karşılığında satın alınmışsa, vade farkı ayrıştırılmaksızın, ödenen veya ödenmesi beklenen nakit tutar üzerinden ölçülür. Ayrıca inşası normal şartlar altında bir yıldan daha uzun süren maddi duran varlıklar için katlanılan borçlanma maliyetleri kullanıma hazır hale geldiği tarihe kadar maddi duran varlığın maliyetine dâhil edilir. Ancak varlık, bir yıldan uzun vadeli bir ödeme karşılığında satın alınmışsa, vade farkı ayrıştırılarak peşin fiyat üzerinden (diğer bir ifadeyle işletme peşin ödeme yapmış olsaydı ödeyeceği fiyat üzerinden) ölçülür. Maddi duran varlıklar, sonraki ölçümlerinde birikmiş amortisman ve birikmiş değer düşüklüğü zararları indirilmek suretiyle maliyeti üzerinden veya yeniden değerlenmiş tutarı üzerinden değerlenir. Yeniden değerlenmiş tutar, maddi duran varlığın yeniden değerleme tarihindeki gerçeğe uygun değeridir. Bu tutar, kamu kurumlarınca yetkilendirilmiş kişiler tarafından yada maddi duran varlığın sınıf ve yeri hakkında güncel bilgisi bulunan, gerekli mesleki bilgiye sahip kişiler tarafindan da belirlenebilir. Bir maddi duran varlığın defter değerinin yeniden değerleme sonucunda artması durumunda, bu artış finansal durum tablosunda özkaynaklarda "Yeniden Değerleme Yedeği" kaleminde gösterilir. ( BOBİ FRS Bölüm 12 madde 15,16,17,19) Sonraki dönemlerde varlığın defter değeri yeniden değerleme sonucunda azalırsa, bu azalış önce "Yeniden Değerleme Yedeği" tutarından düşülür, kalan kısım kâr veya zarara yansıtılır. Bir maddi duran varlık finansal tablo dişı bırakıldığında bu varlığa ilişkin olarak yeniden değerleme yedeğinde yer alan birikmiş tutar "Geçmiş Yıllar Kârları/Zararları" kalemine aktarılır. Buradan da görüldüğü gibi maddi duran varlıklardaki değer artışı, ne değerlemenin yapıldığı dönemin ne de satıldığ1 dönemin karını artacak şekilde kar zarar tablosu ile ilişkilendirilmez.

Maddi olmayan duran varlıkların sonraki dönemlerdeki ölçümlerinde yeniden değerleme yöntemi kullanılmaz, birikmiş amortisman ve birikmiş değer düşüklüğü zararları indirilmek suretiyle belirlenen maliyeti üzerinden ölçülür. 
Amortisman işlemleri, maddi ve maddi olmayan duran varlıklarda zorunlu bir uygulama olup, varlığın amortismana tabi tutarının faydalı ömrü süresince sistematik bir şekilde dağıtılması suretiyle gerçekleştirilmekte ve her zaman kıstamortisman uygulanmaktadır ( Yelgen ve Uyar,2018:101). BOBİ FRS'ye göre maddi ve maddi olmayan duran varlıkların faydalı ömrü, faydalı ömrünün sonundaki kalıntı değeri ve amortisman yöntemi, varlığı kullanan işletme tarafından tespit edilmektedir.

BOBİ FRS 18. Bölümündeki "Varlıklarda Değer Düşüklüğü” hükümlerine göre varlıklar, geri kazanılabilir tutarından daha yüksek bir tutarla finansal durum tablosunda izlenemez. Bir varlığın defter değeri geri kazanılabilir tutarından büyükse değer düşüklügü zararı oluşur ve kar zarar tablosunda raporlanır. Geri kazanılabilir tutar, varlığın (veya nakit yaratan birimin) satış maliyetleri düşülmüş gerçeğe uygun değeri ile kullanım değerinden yüksek olanıdır. Bu bölümdeki madde 13,14 ve 15 kapsamında satış maliyetleri düşülmüş gerçeğe uygun değer, bir varlığın, bilgili ve istekli taraflar arasında karşılıklı pazarlık ortamında piyasa şartları çerçevesindeki satış tutarından, elden çıkarma maliyetleri indirildikten sonra elde edilebilecek tutardır. Kullanım değeri ise BOBİ FRS 15 ile 22. maddeleri gereğince bir varlıktan elde edilmesi beklenen gelecekteki nakit akışlarının bugünkü değeridir.

$\mathrm{Bu}$ uygulamalar ile maddi ve maddi olmayan duran varlıkların, ihtiyatlılık ilkesine uygun olarak finansal durum tablosunda düşük olan değer ile raporlanması sağlanmaktadır. Amortisman giderlerinin hesaplanmasına ve değer azalışlarının raporlanmasına ilişkin düzenlemeler, varlıklardaki gerçek değer kayıplarının gider olarak kaydını ve ihtiyatlılık ilkesine uygun olarak giderlerin olduğundan düşük hesaplanmaması temel ilkesinin gereklerini karşılamaktadır.

BOBİ FRS Bölüm 13'de ele alınan yatırım amaçlı gayrimenkuller ilk kayda almadan sonra gerçeğe uygun değer yöntemi ya da maliyet yöntemi uygulanarak ölçülebilir. Bu varlıklar kira geliri veya değer artış kazancı ya da her ikisini birden elde etmek üzere elde tutulduklarından, dönemler itibarıyla gerçeğe uygun değerlerinde meydana gelen değişiklikler kâr veya zarara yansitılır.

BOBİ FRS Bölüm 20'de yabancı para çevrim işlemleri ele alınmıştır. Parasal olmayan kalemlere ilişkin ortaya çıkan kur farkı kazanç veya kayıpları, ilgili kaleme ilişkin değer değişimlerinin yansıtıldığı Kâr veya Zarar Tablosu kalemi kullanılarak kâr veya zarara kaydedilir. Buna göre yabancı para ile borçlanılarak edinilmiş olan stoklar, finansal varlıklar ve maddi olmayan duran varlıklar için, ortaya çıkan kur artışı hiçbir zaman varlığın maliyetine ilave edilmez veya maliyetten düşülmez. Sadece yeniden değerlenmiş tutarı üzerinden ölçülen maddi duran varlıklara ilişkin yeniden değerlemeden kaynaklanan kur fark1 kazanç veya kayıpları finansal durum tablosunda özkaynaklarda "Yeniden Değerleme Yedeği”nde gösterilir. Maddi duran varlıklar dışında bu kur değişiminin gelir veya gider kaydedilerek kar zarar tablosunda raporlanması gerekir.

BOBİ FRS Bölüm 5'de hasılatın ölçümü ve raporlanması ele alınmıştır. Buna göre hasılat bedelinin, bir y1l veya daha kısa sürede tahsil edilmesinin öngörülmesi durumunda hasılat, vade farkı ayrıştırması yapılmaksızın doğrudan tahsil edilen veya edilmesi beklenen bedel üzerinden ölçülür. Bu bedelin, bir yıldan daha uzun bir vadede tahsil edilmesinin öngörülmesi durumunda ise hasılat, işlemdeki vade farkı ayrıştırılarak ilgili mal veya hizmetin peşin bedeli üzerinden ölçülür, etkin faiz yöntemine göre hesaplanan vade fark1 
tutarı faiz geliri olarak muhasebeleştirilir. Böylece dönem karını değiştirmemekle birlikte, ana faaliyet konusu ile doğrudan ilgili olmayan faiz tutarlarının ana faaliyet sonucunu artırması ve kar zarar tablosu analizlerini olumsuz etkilemesi önlenmiştir.

BOBİ FRS'ye göre, hizmet sunumunun ve inşa sözleşmesinin sonucu güvenilir olarak tahmin edilemiyorsa geri kazanılması beklenen gider tutarı kadar hasılat muhasebeleştirilmekte ve ilgili hizmet sunumu ve inşa sözleşmesine ilişkin herhangi bir kâr ortaya çıkmamaktadır. Hizmet sunumu ve inşa sözleşmesine ilişkin sonucun güvenilir şekilde tahmin edilemediği ve giderlerin de geri kazanımlarının beklenmediği durumlarda ise hasılat kayda alınmamakta, giderler kâr veya zarara yansitılmaktadır ( Sabuncu, 2018:741)

\subsection{Yükümlülüklerin ve Giderlerin Olduğundan Düşük Raporlanmaması}

BOBİ FRS Bölüm 16 gereğince devlet teşvikleri, alınan ya da alınacak olan varlığın gerçeğe uygun değeri üzerinden ölçülür. Piyasa faiz oranından düşük bir faiz oranıyla devletten alınan krediler, bu kredi için devlete yapılacak geri ödemelerin benzer bir kredi için uygulanan piyasa faiz oranıyla iskonto edilmesiyle hesaplanan bugünkü değeri üzerinden ölçülerek finansal durum tablosunda "Diğer Finansal Yükümlülükler" kalemi içinde gösterilir. Devletten alınan kredi tutarı ile finansal durum tablosuna yansıtılan finansal yükümlülük arasındaki fark devlet teşviki olarak muhasebeleştirilir. BOBİ FRS Bölüm 16 madde 8,9)

BOBİ FRS 19. bölümde finansal durum tablosuna yükümlülük olarak ve diğer bir varlığın maliyetine dâhil edilmediği sürece gider olarak kayda alınan karşılıklar ele alınmıştır. Karşılık, gerçekleşme zamanı veya tutarı belli olmayan yükümlülüktür. Karşılıklara örnek olarak garantilere, davalara, müşteri iadelerine, bir tesisin kapatılmasına ve yeniden yapılandırılmasına ilişkin yükümlülükler gösterilebilir. İşletmelerin bugünkü değer hesaplaması yapmadan karşılık tutarını yükümlülüğün yerine getirilmesi için yapılması beklenen harcama tutarı üzerinden ölçmesi mümkündür. Bununla birlikte paranın zaman değerinin etkisinin önemli olduğu durumlarda karşıllk tutarı, yükümlülüğün yerine getirilmesi için yapılması beklenen harcamaların bugünkü değeri üzerinden ölçülebilir. Bugünkü değerin hesaplanması durumunda paranın zaman değerine ilişkin cari piyasa değerlendirmelerini yansitan iskonto oranı (veya oranları) kullanılır. İlgili olduğu raporlama dönemi sonu itibarıyla kıdem tazminatı yükümlülükleri tahmin edilir ve bu tahmin nedeniyle cari dönemde ortaya çıkan kıdem tazminatı yükümlülük artışları hesaplanarak giderleştirilir.

Karşılığa ilişkin tahmini ödeme tutarının ölçümünde işletmenin muhakemede bulunması gerekir. İşletmenin muhakemesi benzer işlemlerden kaynaklanan deneyimleri ve bazı durumlarda bağımsız uzmanlardan alınan değerlendirmeleri yansıtmalıdır( Arar,2018:97)

$\mathrm{Bu}$ düzenlemelere göre, işletmenin olası yükümlülüklerini hesaplayarak finansal durum tablosunda borç olarak ve kar zarar tablosunda gider olarak raporlaması gerekmektedir. Böylece finansal durum tablosunun pasifinde yükümlülüklerin, kar ve zarar tablosunda da giderlerin olduğundan düşük raporlanmaması sağlanarak ihtiyatlılık ilkesinin gereği karşılanmaktadır. 


\section{SONUÇ}

Türkiye Finansal Raporlama Standartları ile büyük ölçüde uyumlu olan, ancak kolaylaştırıcı yöntemler ile sadeleştirilmiş bulunan BOBİ FRS'de ihtiyatlılık ilkesinin gereğini karşılayan düzenlemeler bulunmaktadır. Öncelikle BOBİ FRS'de, varlıkların olduğundan yüksek raporlanmaması ilkesine uygun düzenlemeler bulunmaktadır. Bir yıl veya daha kısa vadeli bir ödeme karşılığında satın alınan stoklar, maddi ve maddi olmayan duran varlıklar, eğer bir yıldan uzun vadeli bir ödeme karşılığında satın alınmışsa, vade farkı ayrıştırılarak peşin fiyat üzerinden ölçülür ve raporlanır. Ayrıca kur farkının varlıkların maliyet değerini artırması ya da azaltması söz konusu değildir.

Gerçeğe uygun değer ile ölçülen canlı varlıklar, hisse senetleri ve yatırım amaçlı gayrimenkuller için gerçeğe uygun değer farkları kar zarara yansıtılmaktadır. Ancak maliyet yöntemi ile raporlanan canlı varlıklarda, itfa edilmiş değeri, maliyet bedeli veya itibari değeri üzerinden ölçülen tüm finansal varlıklarda, stoklarda, maddi ve maddi olmayan duran varlıklarda, eğer dönem sonunda değer düşüklüğü tespit edilmişse, bu değer düşüklüğü finansal durum tablosunda raporlanır ve bu tutar gider olarak kaydedilir. Böylece bir yandan varlıkların düşük değer ile raporlanması sağlanır, öte yandan dönem karının yüksek hesaplanması engellenir. Sadece maddi duran varlıklar için kullanılan yeniden değerleme yönteminde ise ortaya çıkan değer artışı gelir olarak kayıtlanmaz, bir özkaynak hesabına kayıtlanır. Dolayısıyla ihtiyatlılık ilkesine uygun davranılarak değer artışının dönem karını artırması engellenir. Özkaynaklardaki bu değer artışının sermayeye aktarılarak yok edilmesi mümkündür. Varlığın satılması durumunda bu değer artışının "Geçmiş Yıllar Karı" na aktarılması gerektiğinden satış karını artırması engellenmiştir. Buna göre yeniden değerleme yönteminin uygulanmasında da ihtiyatlılık ilkesine aykırı davranılmamaktadır.

İhtiyatlılık ilkesine göre olduğundan düşük raporlanmaması için sadece kesinleşmiş yükümlülükler değil, olası yükümlükler de raporlanmalıdır. BOBİ FRS'de devlet teşvikleri ve karşılıklar ile ilgili düzenlemeler bu ihtiyacı karşılamaktadır. İşletmenin sürdürülebilirliği için ticari karın tespitinde ihtiyatlılık ilkesinin uygulanması gerekir. Bu nedenle ticari karın tespiti ile ilgili ayrıntılı düzenlemelerin bulunduğu BOBİ FRS'de işletmelerin ihtiyatlı davranmasını gerektiren hükümler bulunmaktadır. Benzer çalışmaların TFRS ilgili olarak da yapılması mümkündür.

\section{KAYNAKLAR}

Ataman, Başak (2017), "TFRS Tam Set İle BOBİ FRS' larına Genel Bakış Ve Değerlendirme”, Editörler: Çalıyurt, Kıymet Tunca ve Süleyman Gökhan Günay: Prof. Dr. Fehmi Yıldız Anısına Muhasebe Finans Ve Denetimde Güncel Konular 2017, Trakya Üniversitesi Matbaası, Trakya Üniversitesi Bilimsel Araştırma Projesi 2017/174, Trakya Üniversitesi Yayın No:191, Edirne.

Arar, Mustafa (2018), BOBİ FRS Muhasebesi, Kitap-1, www.bobiturk.com

Gücenme Gençoğlu, Ümit. (2017), “Temel Konularda BOBİ FRS ve TMS/TFRS Karşılaştırılması”, Muhasebe ve Finansman Dergisi, 76, ss. 1-24. 
Kamu Gözetimi, Muhasebe ve Denetim Standartları Kurumu ( 2017), Büyük Ve Orta Boy İşletmeler İçin Finansal Raporlama Standardı Hakkında Tebliğ, 29 Temmuz 2017 tarihli ve 30138 (Mükerrer) sayılı Resmi Gazete

Sabuncu, Birsel( 2018) ,"Büyük Ve Orta Boy İşletmeler İçin Finansal Raporlama Standardı Ve Tekdüzen Muhasebe Sistemi Açısından Hasılatın Ölçüm Ve Muhasebeleştirilmesinin İncelenmesi”,

Muhasebe Bilim Dünyası Dergisi Aralık 2018; 20(4); ss. 738-760

Yelgen, Esin - Uyar, Süleyman( 2018), “BOBİ FRS Açısından Maddi Duran Varlıkların Muhasebeleştirilmesi”, Muhasebe ve Vergi Uygulamaları Dergisi Nisan 2018; Özel Say1: ss. 98-109

Gökçen, Gürbüz- Öztürk, Erkan - Güleç, Ömer Faruk (2018), “BOBİ FRS VE TFRS’nin Finansal Raporlara Etkileri Açısından Karşılaştırılması”, Finans Ekonomi ve Sosyal Araştırmalar Dergisi (FESA),Cilt 3, Sayı 2,ss. 437-457 
The Journal of Accounting and Finance- August 2019 Special Issue 345-354 